\title{
Gp120 activates children's brain endothelial cells via CD4
}

\author{
Monique F Stins, ${ }^{1,7}$ Yamin Shen, ${ }^{5}$ Sheng He Huang, ${ }^{1,3}$ Floyd Gilles, ${ }^{2,6}$ Vijay K Kalra, ${ }^{5}$ \\ and Kwang Sik Kim ${ }^{1,3,4,7}$ \\ ${ }^{1}$ Divisions of Infectious Diseases; ${ }^{2}$ Neurology, Childrens Hospital Los Angeles, Los Angeles, California, USA; \\ ${ }^{3}$ Departments of Pediatrics; ${ }^{4}$ Molecular Microbiology \& Immunology; ${ }^{5}$ Biochemistry and Molecular Biology; ${ }^{6}$ Pathology, \\ USC School of Medicine, Los Angeles, California, USA; and ${ }^{7}$ Department of Pediatrics, Division of Infectious Diseases, \\ Johns Hopkins University School of Medicine, Baltimore, Maryland, USA
}

\begin{abstract}
Encephalopathy represents a common and serious manifestation of HIV-1 infection in children, but its pathogenesis is unclear. We demonstrated that gp120 activated human brain microvascular endothelial cells (HBMEC) derived from children in up-regulating ICAM-1 and VCAM-1 expression, IL-6 secretion and increased monocyte transmigration across monolayers. Another novel observation was our demonstration of CD4 in isolated HBMEC and on microvessels of children's brain cryosections. Gp120-induced monocyte migration was inhibited by anti-gp120 and anti-CD4 antibodies. This is the first demonstration that gp120 activates HBMEC via CD4, which may contribute to the development of HIV-1 encephalopathy in children. Journal of NeuroVirology $(2001) 7,125-134$.
\end{abstract}

Keywords: human cerebral microvessel endothelium; HIV-1; gp120; CD4; VCAM-1; ICAM-1; transendothelial migration of monocytes

\section{Introduction}

Encephalopathy represents a common and serious manifestation of HIV-1 infection in children. Approximately half of children with AIDS develop central nervous system (CNS) complications, which are directly attributable to HIV-1 infection. The virus has been shown to enter the CNS early in the course of HIV-1 infection (Epstein et al, 1986; Wiley et al, 1986; Berger et al, 1987; Grant et al, 1987). At present, it is unclear how HIV-1 enters the brain and causes encephalopathy. HIV-1 may directly infect brain endothelium (Moses et al, 1993; Poland et al, 1995; Edinger et al, 1997), enter endothelium via absorptive endocytosis (Banks et al, 1997) or enter the CNS using the Trojan Horse mechanism via transmigration of HIV-1 infected monocytes (Persidsky et al, 1997). Once HIV-1 is inside the CNS, a cascade of events is triggered, which include infection of microglia, secretion of arachidonic acid metabolites, IL-1, TNF- $\alpha$,

Address correspondence to Kwang Sik Kim, MD, Division of Infectious Diseases, Johns Hopkins University School of Medicine, 600 North Wolfe Street, Park 256, Baltimore, MD 21287, USA. E-mail: kwangkim@jhmi.edu

Received 22 August 2000; revised 21 November 2000; accepted 18 December 2000
TGF- $\beta 1$, macrophage colony stimulating factor, nitric oxide, platelet-activating factor, IL-6, chemoattractants for enhancing transmigration of HIV-1 infected monocytes/macrophages (Wahl et al, 1989; Lipton et al, 1994; Koka et al, 1995; Lafeuillade et al, 1996; Hittinger et al, 1998) and neuronal apoptosis (Bagetta et al, 1995). All these events potentially contribute to the pathogenesis of HIV-1 encephalopathy.

In HIV-infected patients, HIV-1, viral cofactors or proteins (e.g., tat or gp120 shed into the circulation by HIV-1 and HIV-1-infected cells), or viral-induced cytokines (e.g. TNF $\alpha$, IL-6) may act on the brain endothelium, which constitutes the blood-brain barrier (BBB) and allow the entry of HIV-1 and/or HIV1-infected monocytes/macrophages into the CNS. Since little is known about the role of brain endothelium in the pathogenesis of HIV-1 encephalopathy, we developed an in vitro model of the BBB by culturing brain microvascular endothelial cells from children. We showed that children's HBMEC express CD4 and gp120 activates HBMEC in a CD4-dependent manner.

\section{Results}

CD4 is present on isolated pediatric HBMEC HB MEC were positive for Factor VIII-Rag, gamma 

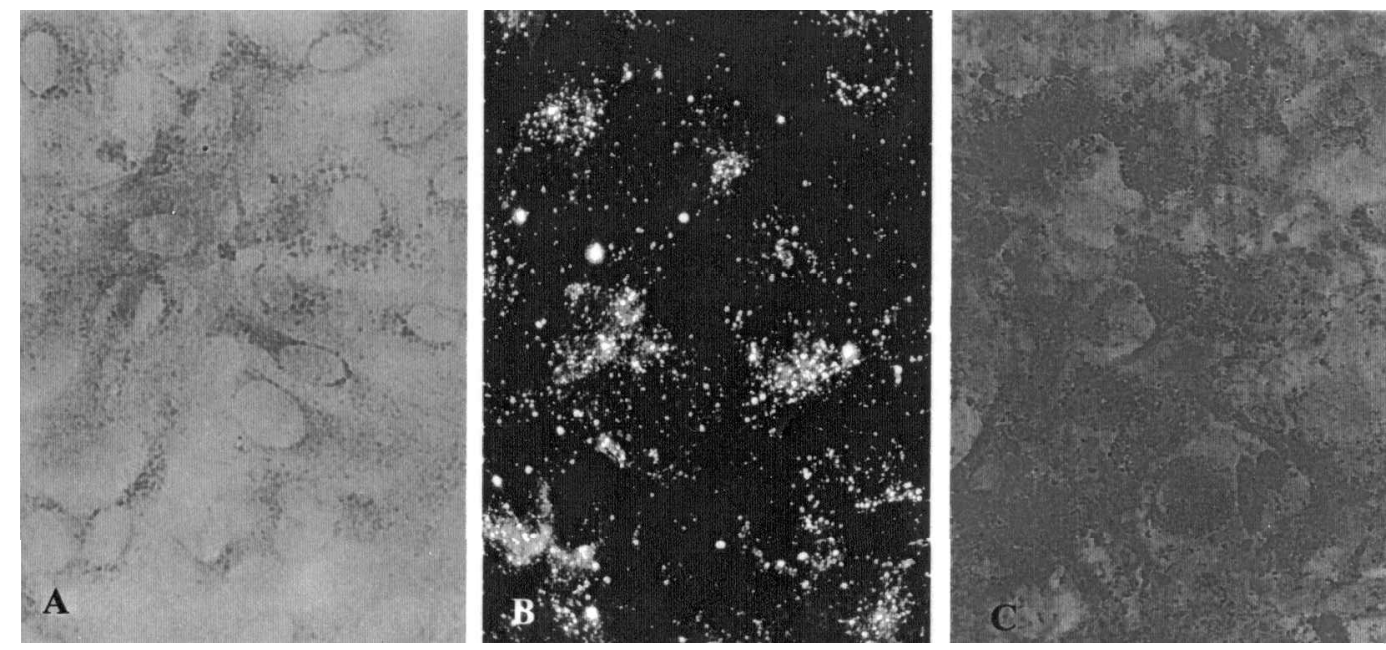

Figure 1 Characterization of human brain endothelial cells from children. (A) Positive immunoperoxidase staining for Factor VIII-Rag in HBMEC. (B) Uptake of Dil-labeled acetylated LDL by HBMEC. (C) Positive gamma glutamyl transpeptidase staining.

glutamyl transpeptidase, and took up acetylated LDL (Figure 1A-C). No GFAP positive cells were found and very few cells stained positive for alpha smooth muscle cells, indicating that HBMEC cultures were more than $95 \%$ pure. FACS sorting of HBMEC resulted in $>99 \%$ purity (Stins et al, 1997).

The presence of CD4 on pediatric HBMEC was shown by three different techniques. First, FACS analysis of HBMEC incubated with anti-CD4 monoclonal antibody revealed that $58 \%$ cells were positive for CD4 (Figure 2A). Second, RT-PCR of FACS sorted ( $>99 \%$ pure) pediatric HBMEC as well as CD4-positive lymphocytes revealed the PCR product $(0.76 \mathrm{~kb})$ corresponding to the expected size for the specific primers of CD4 (Figure 2B) and DNA sequencing of the PCR product verified CD4 (Parnes, 1989). A negative control of HBMEC without RT step confirmed that the product was not due to the presence of genomic DNA. In contrast, using the same primers, CD4 could not be detected from HUVEC (Figure 2B) and adult HBMEC (not shown). Third, immunocytochemistry of HBMEC with four different anti CD4 monoclonal antibodies revealed the presence of $\mathrm{CD} 4$ as indicated by the red precipitates (Figure 2C). Immunocytochemistry of HBMEC derived from three other children also showed positive staining for CD4, indicating that the presence of CD4 on brain endothelium is not unique to a particular child. Under similar conditions HUVEC did not show any staining for CD4 (Figure 2D). These findings indicate that pediatric HBMEC possess CD4, whereas CD4 is absent from HUVEC and adult HBMEC.

CD4 is present on microvessels in frozen sections of children's brains Frozen sections of children's brain specimens incubated with anti-CD4 antibodies revealed a clear-cut staining associated with microvessel structures, indicating the presence of CD4
(Figure 2E). In contrast, CD4 staining was negative in sections derived from adult brain (not shown). These findings show that CD4 is present on brain microvessels from children and support our demonstration that CD4 is present on pediatric brain endothelial cells.

Gp120 activated children's HBMEC: cell adhesion molecule expression and IL-6 secretion Gp120, shed from HIV-1 and HIV-1 infected cells, is shown to be present in the blood of HIV-1-infected patients (Schneider et al, 1986; Oh et al, 1992) and thus brain endothelium is likely to be exposed to circulating gp120. Since the major receptor for gp120 is the cell surface molecule CD4, we investigated whether pediatric HBMEC, which possesses CD4, would be responsive to gp120. Immunocytochemistry showed that gp120 concentrations ranging from 0.01 to $5 \mu \mathrm{g} / \mathrm{ml}$ were able to induce VCAM-1 and increase ICAM-1 expression after 4-24 h of incubation (not shown). Quantitation of VCAM-1/ICAM1 expression by ELISA showed upregulation after 6-h incubation with gp120 derived from different T-tropic viruses, e.g., HIV-1 sf2, 2003 LAV, 2003 CM, 2003MN (Figure 3A). No effect of gp120 on VCAM-1/ICAM-1 expression was found on HUVEC, whereas both LPS and TNF $\alpha$ (positive controls), as expected, induced robust expression of cell adhesion molecules on HUVEC (Figure 3B). Polymyxin B did not affect gp120-induced cell adhesion molecule expression on pediatric HBMEC (not shown), indicating that the gp120 effect was not due to a contamination of LPS. Gp120 (5 $\mu \mathrm{g} / \mathrm{ml})$ was able to induce IL-6 release from pediatric HBMEC, that is, $565 \mathrm{pg} / \mathrm{ml}$ of IL-6 was found in the medium after $6 \mathrm{~h}$ of incubation while $\mathrm{TNF} \alpha$ as a positive control released $725 \mathrm{pg} / \mathrm{ml}$. IL-6 release was not detectable in pediatric HBMEC incubated with medium alone. 

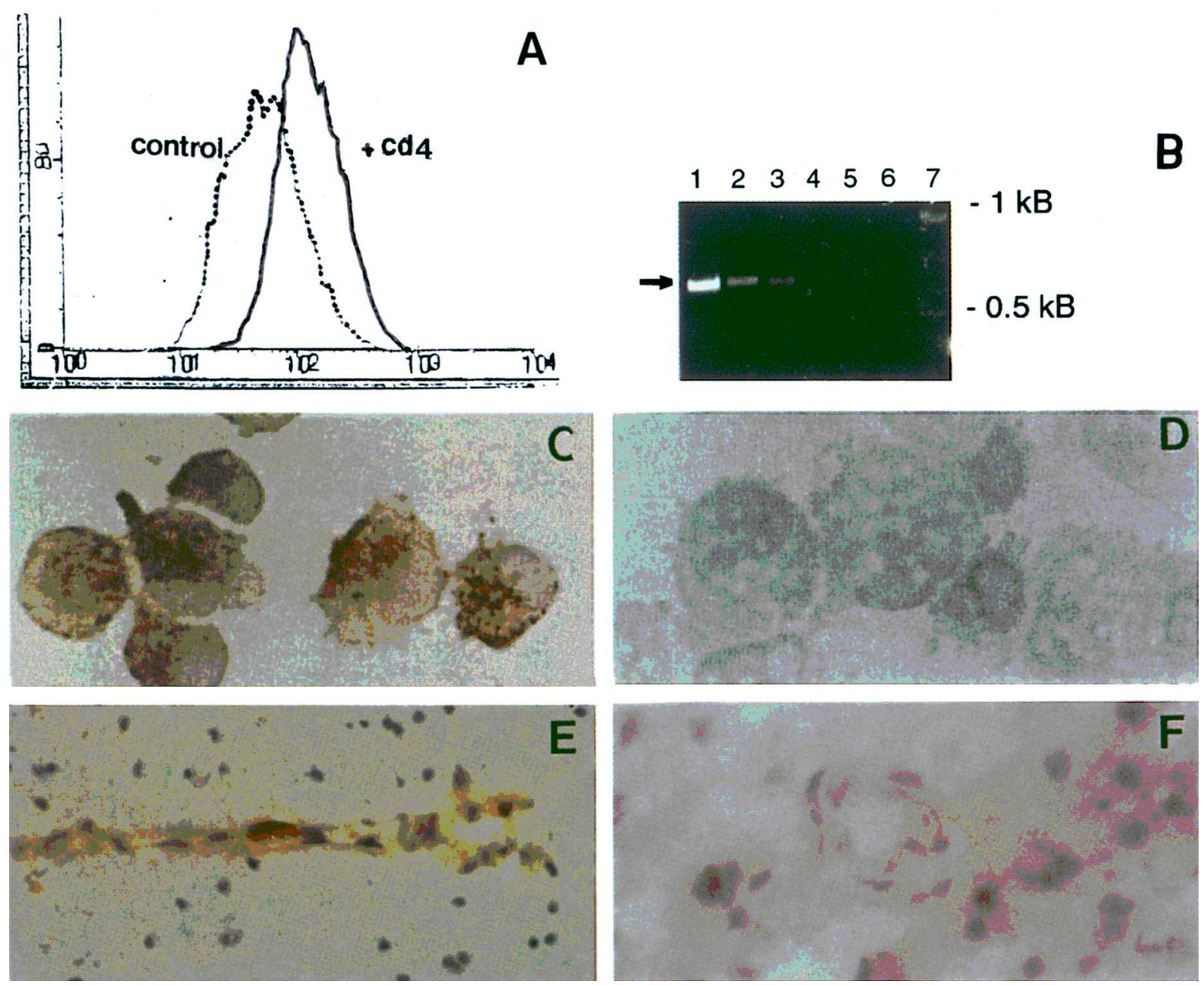

Figure 2 Presence of CD4 on pediatric brain endothelial cells. (A) FACS analysis of pediatric HBMEC with anti-CD4 antibody. The shift to the right indicates the presence of a CD4-positive population. The left curve is staining with a control-irrelevant antibody. (B) RT-PCR product of $0.76 \mathrm{~Kb}$ (arrow) of FACS-sorted pediatric HBMEC indicates the presence of CD4. Lane 1, cDNA library of pediatric HBMEC; lane 2, HBMEC from a child; lane 3, CD4+ Lymphocytes; lane 4, HUVEC; lane 5, without template; lane 6, without RT step; lane 7, Kb markers. (C) Immunocytochemistry for CD4. The red precipitate indicates the presence of CD4 on pediatric HBMEC. (D) The absence of immunostaining for CD4 on HUVEC. (E) Red peroxidase staining indicates the presence of CD4 on a microvessel structure in frozen section of pediatric brain. (F) Absence of staining for CD4 on microvessel structures in frozen section of adult brain.

Gp120-induced transmigration of monocytes across children's HBMEC monolayers involves CD4 Because gp120 increased adhesion molecule expression on HBMEC, we next investigated the effect of gp120 on transendothelial migration of monocytes. Freshly isolated monocytes or vitamin $\mathrm{D}_{3}$ differentiated HL60 cells were added to the upper compartment of Transwell ${ }^{\mathrm{TM}}$ tissue culture inserts containing pediatric HBMEC monolayers. Both gp120 $(0.5 \mu \mathrm{g} / \mathrm{ml})$ and LPS (100 $\mathrm{ng} / \mathrm{ml})$ enhanced monocyte transmigration over an 8-h period (3.1-fold and 1.9-fold increases, respectively) (Figure 4A). Figure 4B shows that gp120-induced monocyte migration was inhibited by monoclonal antibodies against CD4 and gp120, while irrelevant antibody (anti-HLA-I) did not have such an inhibitory effect. Polymyxin B had no effect on gp120-induced trans- migration in HBMEC, indicating that gp120-induced transmigration was not due to LPS contamination. In contrast, gp120 did not induce any significant increase in monocyte migration in HUVEC, while LPS induced a 3.4-fold increase in monocyte transmigration (Figure 4C). Similar results were obtained with freshly isolated monocytes. These results indicate that increased transmigration of monocytes/HL60 cells across HBMEC in response to gp120 is specific for pediatric brain endothelial cells, which occurs via a CD4-dependent manner. Because endothelial barrier models were used ( $>99 \%$ pure HBMEC), it is unlikely that our results are due to contaminating nonendothelial cells.

Involvement of chemokine receptors in gp120induced transmigration of monocytes across children's HBMEC monolayers As gp120 is a ligand 

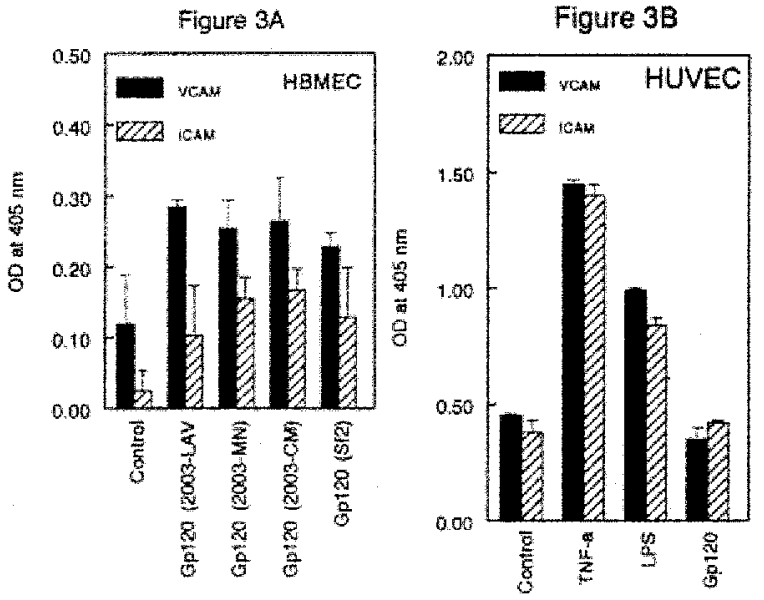

Figure 3 Gp120 increases ICAM-1 and VCAM-1 expression on pediatric HBMEC as assessed by ELISA. (A) Gp120 from different HIV-1 $(0.5 \mu \mathrm{g} / \mathrm{ml})$ increases ICAM-1 and VCAM-1 expression on pediatric HBMEC. Bars indicate standard deviation. Gp120induced increase in VCAM/ICAM expression was statistically different from the control (For VCAM: $F=8.27$, T range is $4.2-4.9$, $P<0.002$ and for ICAM: $F=387$, T range is $19.4-35, P<0.001)$. (B) TNF $\alpha(10 \mathrm{ng} / \mathrm{ml})$ and LPS (50 ng/ml) but not gp120 $(0.5 \mu \mathrm{g} / \mathrm{ml})$ increase VCAM-1 and ICAM-1 expression on HUVEC. Bars indicate standard deviation. TNF $\alpha$ - and LPS-induced increases in VCAM/ICAM expression were statistically different from the control, whereas gp120 did not differ from the control $(F=1062, \mathrm{~T}$ range $=0.01-45, P<0.001)$. for both CD4 and chemokine coreceptors, the possible involvement of chemokine coreceptors in gp120mediated transmigration was investigated (Figure 5). RANTES (100 ng/ml) increased monocyte transmigration by $21 \%$, however this increase was not statistically different from the control. Gp120 increased monocyte migration by $100 \%$ and antibodies against CXCR4, CCR3, CCR5, or isotype-matched control antibody did not significantly affect gp120-induced transmigration. This indicates that chemokine coreceptors do not play a major role in gp120induced transmigration of monocytes across pediatric HBMEC.

\section{Discussion}

In children, HIV-1 infection is frequently accompanied by serious neurologic dysfunction. Epstein et al (1986), have reported that progressive encephalopathy occurs in more than $50 \%$ of children with HIV-1 infection and the outcome is usually fatal. More recently, Cooper et al (1998) reported the presence of encephalopathy in $27 \%$ of HIV-1-infected children. Moreover, encephalopathy has been shown to represent the first AIDS-defining condition in 67\% of the children and in $26 \%$ of children it was the only AIDS-defining condition (Cooper et al, 1998). HIV-1-associated neurologic dysfunction occurs in the absence of opportunistic infections, implying the limited role of co-infection in the pathogenesis of HIV-1 encephalopathy (Cooper et al, 1998). The CNS,
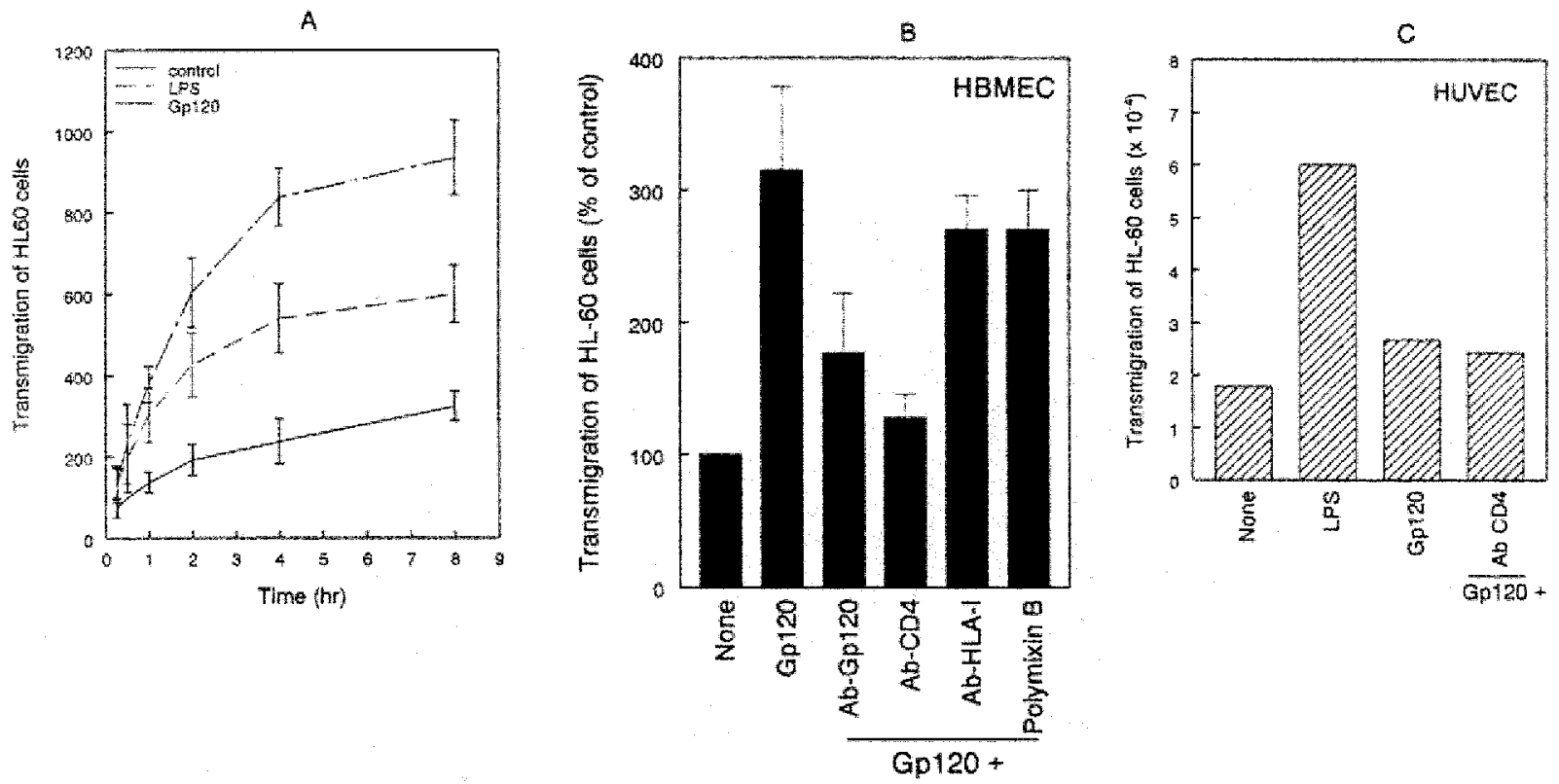

Figure 4 Monocyte transmigration across pediatric HBMEC monolayers. (A) A time-dependent increase in transmigration of HL60 cells was induced by both gp120 $(0.5 \mu \mathrm{g} / \mathrm{ml})$ and LPS $(100 \mathrm{ng} / \mathrm{ml})$. Bars indicate standard deviation. (B) Gp120 (0.5 $\mu \mathrm{g} / \mathrm{ml}) \mathrm{induced}$ transmigration at $2 \mathrm{~h}$ was inhibited by anti-CD4 and anti-gp120 antibodies (T range $=4.6-6.2, P<0.001$ ), but not by anti-HLA-1 antibody (control). Addition of polymyxin B did not inhibit gp120-induced monocyte transmigration. Bars indicate standard deviation. (C) Gp120 $(0.5 \mu \mathrm{g} / \mathrm{ml})$ for $4 \mathrm{~h}$ did not increase monocyte transmigration across HUVEC, whereas LPS (100 ng/ml) (positive control) increased monocyte migration. The addition of anti-gp120 or anti-CD4 antibody did not affect monocyte transmigration in the presence of gp120 in HUVEC (mean of duplicate experiments). 


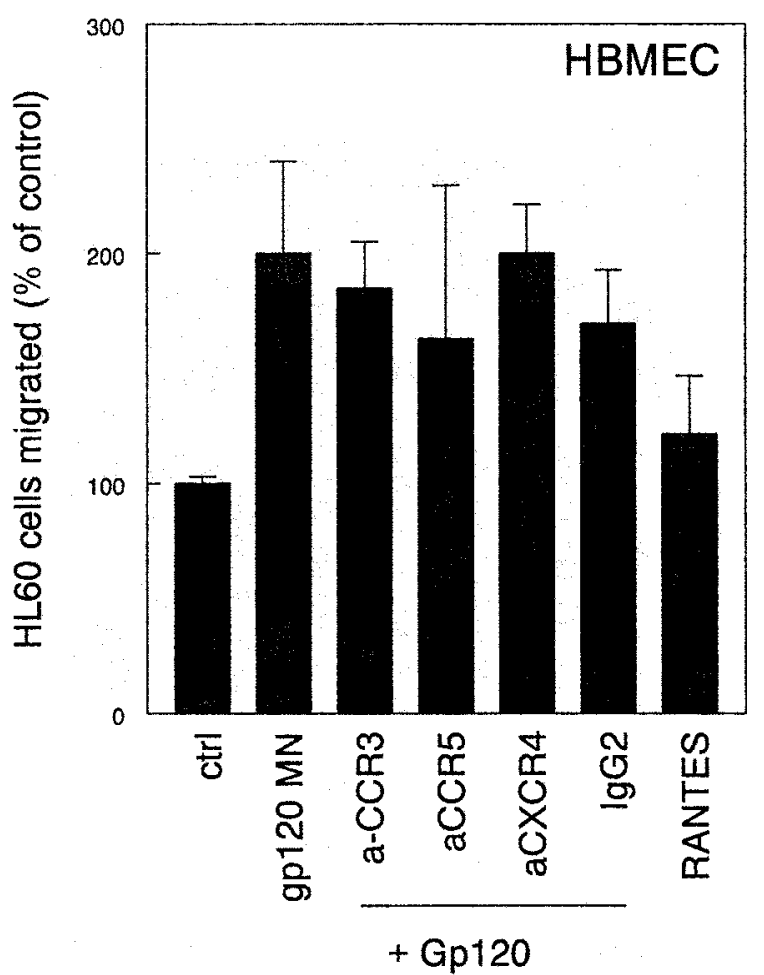

Figure 5 Involvement of chemokine coreceptors in monocyte transmigration across pediatric HBMEC monolayers. RANTES did not significantly increase transmigration of monocytes. Antibodies against CXCR4, CCR3 and CCR5 (up to $5 \mu \mathrm{g} / \mathrm{ml}$ ) did not decrease gp120 $(0.5 \mu \mathrm{g} / \mathrm{ml})$-induced transmigration at $4 \mathrm{~h}$ and an irrelevant antibody did not show any effect (control) $(F=2.5$, T range $=0.9-$ $1.42, P$ range $=0.36-0.17$, nonsignificant $)$. Bars indicate standard deviation.

along with the immune system, are therefore important targets for HIV-1, especially in children.

It is unclear how HIV-1 enters the CNS and causes encephalopathy. There are several hypotheses about how HIV-1 crosses the brain endothelium and enters the CNS. For example, HIV-1 may infect the brain endothelium (Moses et al, 1993; Poland et al, 1995; Edinger et al, 1997). Brain endothelial cells from monkey and cat have been shown to be infected with SIV or FIV, respectively (Lafon et al, 1993; Mankowski et al, 1994; Edinger et al, 1997; Strelow et al, 1998). It remains, however, controversial whether brain endothelial cells derived from humans can be infected with HIV-1. Another possibility is that cell associated HIV-1 may cross the brain endothelium into the CNS as demonstrated by the presence of monocyte/macrophages around the brain microvessels in patients with HIV-1 CNS infection (Wiley et al, 1986). In addition, an impairment of the barrier function of the endothelium may allow cell-free and cell-associated HIV-1 to enter the CNS. For example, signs of endothelial activation and damage have been reported in HIV-1-infected patients, e.g., increases in MHC expression, VCAM-1 expression, monocyte adherence, von Willebrand factor concentration and plasminogen activator inhibitor, decreases in protein
$S$ levels, and leakage of serum components into the CNS (Elovaara et al, 1991; Lafeuillade et al, 1992; Singer et al, 1994; Zietz et al, 1996; Stefano et al, 1998). We have previously shown that TNF $\alpha$ activation of the brain endothelium increases HIV-1 crossing of the BBB by a paracellular mechanism (Fiala et al, 1997). Increased VCAM-1 expression and monocytes adherence to endothelium have also been reported in SIV infection in macaques (Sasseville et al, 1992; Sasseville et al, 1994). Circulating gp120 (Schneider et al, 1986; Gelderblom et al, 1987; Willey et al, 1994;) is also likely to come into contact with the brain endothelium.

In this study, we showed for the first time that gp120 is able to activate human brain endothelial cells, e.g., IL-6 secretion, VCAM-1, ICAM-1 expression, and monocyte migration. Gp120 concentrations in plasma and tissues of HIV-infected patients are unclear but the concentrations used in this report $(0.01$ to $5 \mu \mathrm{g} / \mathrm{ml})$ are similar to those reported in the serum of AIDS patients (Oh et al, 1992). More importantly, we showed for the first time that CD4 is present on isolated HBMEC from children as shown by immunocytochemistry, RT-PCR, and FACS analysis. The presence of CD4 on pediatric brain endothelium in situ was demonstrated on frozen sections of brain tissues. The involvement of CD4 in gp120-induced monocyte migration was demonstrated by inhibition with anti-CD4 antibodies. Gp120-mediated activation of HBMEC was specific to pediatric brain endothelial cells. Gp120 did not induce VCAM1/ICAM-1 up-regulation and monocyte transmigration in HUVEC, and we failed to demonstrate CD4 on HUVEC. These findings indicate that CD4 in pediatric brain endothelial cells is functionally interactive with gp120 and contributes to gp120-mediated activation of HBMEC.

CD4 is not restricted to the immune system and also shown to be present on glial cells, neurons, and colorectal epithelial cells (Maddon et al, 1986; Cheng-Mayer et al, 1987; Funke et al, 1987; Adachi et al, 1998). It is, however, controversial whether CD4 is present on endothelial cells. CD4 has been reported to be present on microvascular endothelial cells of the human hepatic sinusoid (Nagura et al, 1986). In contrast, CD4 was found to be absent on portal liver endothelium and macrovascular HUVEC (Lafon et al, 1992; Conaldi et al, 1995; Corbeil et al, 1995). Other investigators also failed to demonstrate CD4 on brain endothelial cells derived from adults (Moses et al, 1993; Poland et al, 1995). In agreement with those findings, we were not able to show the presence of CD4 on adults' human brain endothelial cells. These findings suggest that the role of brain endothelial cells in the pathogenesis of HIV-1 encephalopathy may differ between children and adults. An equally intriguing question is whether or not pediatric HBMEC, which possesses CD4, can be permissive for HIV-1 infection. Of interest, our preliminary investigations revealed that 
pediatric HBMEC expresses chemokine coreceptors, CCR3 and CCR5. However, as shown in this report, antibodies against both $\alpha$ - and $\beta$-chemokine coreceptors did not affect monocyte transmigration, suggesting that chemokine coreceptors are not likely to be a major contributor to gp120-mediated transmigration of monocytes across pediatric HBMEC. In contrast, Edinger et al (1997) have shown that CCR5 can serve as a CD4-independent receptor in simian immunodeficiency virus (SIV) infection of Rhesus brain capillary endothelial cells. Additional studies are needed to elucidate the role of chemokine receptors in HIV-1 and SIV activation/infection of brain microvascular endothelial cells in humans and primates.

We also showed that gp120 increased monocyte transmigration across pediatric HBMEC monolayers. We have previously shown that immune activation of monocytes increases transmigration of monocytes across both adult and pediatric HBMEC monolayers (Persidsky et al, 1997). Thus, it is possible that increased transendothelial migration of monocytes may be due to the activation of monocytes by gp120. However, gp120 did not induce significant increase in migration of monocytes across HUVEC, suggesting that gp120-mediated activation of monocytes is unlikely to be involved in gp120-mediated enhancement in transendothelial migration of monocytes. In addition, we have previously shown that HIV-1 infection of monocytes contributed to transendothelial migration of monocytes (Persidsky et al, 1997). Independently, we observed that gp120 increased phosphorylation of PECAM-1 (unpublished results). We have previously shown that PECAM-1 phosphorylation is associated with transendothelial migration of monocytes across pediatric HBMEC (Kalra et al, 1996; Sultana et al, 1996). Studies are in progress to elucidate the mechanisms of gp120induced transendothelial migration of monocytes across childrens' HBMEC.

Gp120 has been shown to elicit neurotoxic substances (e.g., cytokines, arachidonic acid metabolites) (Wahl et al, 1989; Lipton et al, 1994; Koka et al, 1995; Yeung et al, 1995) in brain cultures, increase intracellular calcium (Dreyer et al, 1990) and induce apoptosis in neurons (Bagetta et al, 1995; Lannuzel et al, 1997; Hesselgesser et al, 1998). In the present study, we demonstrated that gp120-induced up-regulation of VCAM-1 and ICAM-1 expression and transendothelial migration of monocytes in pediatric HBMEC. Taken together, these findings indicate that gp120 may contribute to the development and progression of HIV-1 CNS infection by allowing increased migration of monocytes across the BBB and also inducing neuronal injury.

In summary, we demonstrated for the first time that gp120 activates pediatric brain microvascular endothelial cells (secretion of IL-6, up-regulation of VCAM-1 and ICAM-1 expression, and monocyte migration) via a CD4-dependent manner.

\section{Materials and methods}

\section{Isolation and culture of human brain microvessel} endothelial cells (HBMEC)

Human brain capillaries were isolated and cultured as described previously (Stins et al, 1997). Briefly, small fragments of cerebral cortex were obtained from surgical resections of 4-7-year-old children with seizure disorders at Childrens Hospital Los Angeles and kept on ice unless otherwise indicated. Adult brain specimen was obtained from adult ( $\sim 35$ years) with seizure disorder. Visible larger blood vessels, if present, were carefully removed. Brain specimens were cut into small pieces and homogenized in Dulbecco's Modification of Eagles Medium containing $2 \%$ fetal bovine serum (DMEM-S) using a Dounce homogenizer with a loose fitting. The homogenate was centrifuged in 15\% dextran in DMEM-S for $10 \mathrm{~min}$ at $10000 \mathrm{~g}$. The pellet containing crude microvessels was further digested in a solution containing $1 \mathrm{mg} / \mathrm{ml}$ collagenase/dispase in DMEM-S for $1 \mathrm{~h}$ at $37^{\circ} \mathrm{C}$. Microvascular capillaries were isolated by absorption to a column of glass beads and washing off the beads.

Human brain microvessels were plated on rat tail collagen and fibronectin coated dishes or glass coverslips and cultured in RPMI 1640-based medium with $10 \%$ fetal bovine serum (FBS), 10\% NuSerum, endothelial cell growth supplement $(30 \mu \mathrm{g} / \mathrm{ml}$ ) (Collaborative Biomedical Products, B\&D, Bedford, MA), heparin $(5 \mathrm{U} / \mathrm{ml})$, L-glutamine ( $2 \mathrm{mM})$, sodium pyruvate $(1 \mathrm{mM})$, MEM nonessential amino acids, MEM vitamins, penicillin, and streptomycin $(100 \mathrm{U} / \mathrm{ml})$ (Irvine Scientific, lrvine, CA). Cultures were incubated at $37^{\circ} \mathrm{C}$ in a humid atmosphere of $5 \% \mathrm{CO}_{2}$ and characterized as described previously (Stins et al, 1997). The endothelial cultures were more than $95 \%$ pure. FACS sorting of pediatric HBMEC was done as previously described (Stins et al, 1997), yielding more than $99 \%$ pure endothelial cell populations.

\section{FACS analysis and Immunocytochemistry}

of pediatric $\mathrm{HBMEC}$ for CD4

Confluent pediatric HBMEC were lifted with EDTA, incubated with mouse monoclonal antibody to CD4 (1:20) (Gentrack, Plymouth Meeting, PA) or nonimmune ascites as a control for $30 \mathrm{~min}$ at $4^{\circ} \mathrm{C}$, washed, incubated with FITC coupled goat anti-mouse lgG (Dako, Carpinteria, CA), fixed with paraformaldehyde and analyzed by flow cytometry on a FACSscan. Lymphocytes known to be positive for CD4 were used as a positive control. Results were reported as percentage positive cells.

Immunocytochemistry for CD4 was done on HBMEC-cytospin slides and frozen sections of pediatric brain tissue using the avidin-biotin complexed to peroxidase (ABC-PO) method (Vector Labs, Burlingame, CA) as described previously (Stins et al, 1997). Anti-CD4 (Dako) was used in 1:20 dilution and CD4 hybridoma antibody SIM2, SIM4 
(1:5 to 1:30) was from Dr James Hildreth obtained through the Reference Reagent Program, DAIDS, NIAID, NIH. Peroxidase color was developed with 3-amino-9-ethylcarbazole according to the manufacturer's instructions (Vector, Burlingame, CA) and cells/sections were counterstained with hematoxylin. Control ascites of nonsecretory myeloma, control isotype-matched antibody (Sigma, St Louis, MO) and omission of the primary and/or secondary antibody resulted in the absence of staining.

\section{RT-PCR amplification of pediatric HBMEC}

Total RNA was isolated from FACS sorted (>99\% pure, clone AS4-3a) pediatric HBMEC (Stins et al, 1997), using the guanidine isothiocyanate method. In addition, RNA was isolated from CD4 lymphocytes and from HUVEC (Clonetics, San Diego, CA). RT-PCR was done as described previously (Huang, 1997). Briefly, $1 \mu \mathrm{g}$ of RNA was added to a mixture of 1X AMV reverse transcription buffer (Promega, Madison, WI), $2.5 \mathrm{mM} \mathrm{MgSO}_{4}, 0.5 \mathrm{mM}$ deoxynucleotide triphosphate (Perkin Elmer, Branchburg, NJ), 50 pmol of each primer, AMV transcriptase, and $T f l$ DNA polymerase (Promega) in a final volume of $50 \mu \mathrm{l}$. Reverse transcription was performed at $48^{\circ} \mathrm{C}$ for $45 \mathrm{~min}$. Amplification was carried out in a Thermocycler (MJ Research, Waltham, MA) for 40 cycles: denaturation for $1 \mathrm{~min}$ at $94^{\circ} \mathrm{C}$; primer annealing for $1 \mathrm{~min}$ at $60^{\circ} \mathrm{C}$; primer extension for $3 \mathrm{~min}$ at $70^{\circ} \mathrm{C}$. The following primers were used for a 0.76-kb CD4 fragment (189953): $5^{\prime}$ primer, $5^{\prime}$ ACTGACCTGTACAGCTTC- $3^{\prime}$, and $3^{\prime}$ primer, 5'-CCAGCATACTGAGGCAAG-3'. These primers were synthesized on an Applied Biosystems 380B DNA synthesizer (Foster City, CA). The PCR product was resolved on $0.8 \%$ agarose gel. The PCR DNA was confirmed by DNA sequencing with sequenase (US Biochemical Corporation, Cleveland, $\mathrm{OH})$.

Activation of pediatric HBMEC by gp120

Confluent pediatric HBMEC were treated with gp120 (0.01-5 $\mu \mathrm{g} / \mathrm{ml}$ ) in RPMI with 10\% FBS for the indicated time. Thereafter, incubation medium was removed and IL-6 secretion was determined by ELISA as previously described (Arditi et al, 1995). Gp120 preparations were obtained through the Reference Reagent Program, DAIDS, NIAID, NIH: gp120 from HIV-SF2 (\#386) from Dr Kathleen Steimer, Chiron Corp (Levy et al, 1984; Sanchez-Pescador et al, 1985; Haigwood et al, 1990; Scandella et al, 1993), gp120 from HIV-1 2003 MN, 2003-LAV, and 2003-CM from MicroGeneSys Inc (Meriden, CT) and gp120 (Clade E) from Mr Steve Showalter and Ms Garcia-Moll (Biomolecular Technology).

Expression of VCAM-1 and ICAM-1 was assessed immunocytochemically on cytospins slides and quantified by ELISA using antibodies against VCAM1 and ICAM-1 (1:1000) (Immunotech, Westbrook,
$\mathrm{ME}$ ) using the ABC-PO or ABC-alkaline phosphatase (ABC-AP) method as described previously (Stins et al, 1997). Briefly, confluent HBMEC was treated with gp120 $(0.5 \mu \mathrm{g} / \mathrm{ml})$ or $\mathrm{TNF} \alpha(10 \mathrm{ng} / \mathrm{ml})$ for the indicated time, fixed with acetone/methanol $(1: 1$, $\mathrm{V}: \mathrm{V})$, incubated with the appropriate antibodies and color developed. For ELISA, ABC-AP was developed using $p$-nitrophenyl phosphate substrate and the absorbency at $405 \mathrm{~nm}$ was read (Molecular Devices, Menlo Park, CA). The results were expressed as relative optical density as mean of duplicate or triplicate $( \pm S D)$ after subtracting the blank value (determined in the absence of the primary antibody).

Gp120 induced transmigration of monocytes across pediatric HBMEC monolayers

To assess the effect of gp120 on monocyte migration across a single cell-type blood-brain barrier model, HBMEC ( $>99 \%$ pure) were seeded on collagen/fibronectin coated Transwell ${ }^{\mathrm{TM}}$ polycarbonate tissue culture inserts (12-well, Corning Costar, Cambridge MA) and grown to confluence. This allows separate access to the upper chamber (500 $\mu \mathrm{l})$ and lower chamber $(1500 \mu \mathrm{l})$. Confluent HBMEC were treated with gp120 $(0.5 \mu \mathrm{g} / \mathrm{ml})$ or LPS (E. coli O111:B4) (50-100 ng/ml) (List Biochemicals, Campbell, CA) for the indicated time periods. Freshly isolated monocytes (Kalra et al, 1994) or monocyte-like vitamin $\mathrm{D}_{3}$-differentiated HL60 cells (Languino et al, 1995; Hickstein et al, 1987) $1 \times 10^{5}$ cells/well (ATCC, Bethesda, MD) were added to the upper chamber and allowed to migrate to the bottom chamber. At the indicated times, 100- $\mu$ l samples from the lower compartment were taken and the number of transmigrated monocytes counted as previously described (Kalra et al, 1996). Similar results were obtained with freshly isolated monoctes and with monocytelike vitamin D3-treated HL60 cells. Monocyte migration was also assessed in the presence of monoclonal antibodies against CD4 $(10-40 \mu \mathrm{g} / \mathrm{ml})$, gp120 (10-40 $\mu \mathrm{g} / \mathrm{ml}$ ), or HLA-1 (Dako, Carpinteria, CA), anti-chemokine receptor antibodies (5-10 $\mu \mathrm{g} / \mathrm{ml})$ or lgG2a (Sigma, St Louis MO). Antibodies against CD4, gp120 and chemokine receptors were from NIH-AIDS Reference Reagent Program, DAIDS, NIAID, and the concentrations used were shown to block ligand and gp120 binding. Monoclonal antibody to CD4 (Q4120) was from Dr Quentin Sattenau (Healey et al, 1990) and monoclonal antibody to HIV-1gp120 (0.5 $\beta)$ was from Dr Shuzo Matsushita (Matsushita et al, 1988). Anti-chemokine receptor monoclonal antibodies included CXCR4 (12G5) from Dr James Hoxie (Endres et al, 1996), CCR5 (2D7) from Pharmigen, and CCR3 (7B11) from Leukocyte Inc (Heath et al, 1997).

\section{Statistical analysis}

For statistical analysis ANOVA with planned pairwise comparison utilizing $\mathrm{T}$ distribution was used. 


\section{Acknowledgements}

The authors thank Ray Chan, Department of Immunology, CHLA for his help with the FACS scan for CD4 and Earl Leonard, Research Insti-

\section{References}

Adachi A, Koenig S, Gendelman HE, Draugerthy AD, Gattoni-Celli S, Fauci AS, Martin MA (1998). Productive and persistent infection of human colorectal cell lines with human immunodeficeincy virus. J Virol 7: 209-213.

Arditi M, Zhou J, Torres M, Durden DL, Stins M, Kim KS (1995). Lipopolysaccharide stimulates the tyrosine phosphorylation of mitogen-activated protein kinases p44, p42, and p41 in vascular endothelial cells in a soluble CD14-dependent manner. Role of protein tyrosine phosphorylation in lipopolysaccharide-induced stimulation of endothelial cells. J Immunol 155: 3994-4003.

Bagetta G, Corasaniti MT, Berliocchi L, Navarra M, FinazziAgro A, Nistico G (1995). HIV-1 gp120 produces DNA fragmentation in the cerebral cortex of rat. Biochem Biophys Res Commun 211: 130-136.

Banks WA, Kastin A, Ackerstrom V (1997). HIV-1 protein gp120 crosses the blood brain barrier; Role of adsorbtive endocytosis. Life Sci 61: 119-125.

Berger JR, Moskowitz L, Fishi M, Kelley, RE (1987). Neurologic disease as the presenting manifestation of aquired immunodeficeincy syndrome. South Med J 80: 683-686.

Cheng-Mayer C, Rutka JT, Rosenblum ML, Hugh T, Sites DP, Levy JA (1987). Human immunodeficiency virus can productively infect cultured human glial cells. Proc Natl Acad Sci USA 84: 3526-3530.

Conaldi PG, Serra C, Dolie A, Basolo F, Falcone F, Mariani G, Speziale P, Toniolo A (1995). Productive HIV infection of human vascular endothelial cells requires cell proliferation and is stimulated by combined treatment with interleukin beta plus TNF alpha. J Med Virol 47: 355-363.

Cooper ER, Hanson C, Diaz C, Mendez H, Abboud R, Nugent R, Pitt J, Rich K, Rodriguez EM, Smeriglio V (1998). Encephalopathy and progression of human immunodeficiency virus disease in a cohort of children with perinatally acquired human immunodeficiency virus infection. Women and Infants Transmission Study Group. J Pediatr 132: 808-812.

Corbeil J, Evans LA, McQueen PW, Vasak E, Edward PD, Richman DD, Penny R, Cooper DA (1995). Productive infection of human umbilical vein endothelial cells and three colon carcinoma cells with HIV-1. Immunol Cell Biol 73: 140-145.

Dreyer EB, Kaiser PK, Offermann JT, Lipton SA (1990). HIV-1 coat protein neurotoxicity prevented by calcium channel antagonists [see comments]. Science 248: 364367.

Edinger AL, Mankowski JL, Doranz BJ, Margulies BJ, Lee B, Rucker J, Sharron M, Hoffman TL, Berson JF, Zink MC, Hirsch VM, Clements JE, Doms RW (1997). CD4independent, CCR5-dependent infection of brain capillary endothelial cells by a neurovirulent simian immunodeficiency virus strain. Proc Natl Acad Sci USA 94: $14742-14747$.

Elovaara I, Seppala I, Kinnunen E, Laaksovirta H (1991). Increased occurrence of free immunoglobulin light chains tute, CHLA for his assistance with the statistical analysis. This work was supported by Pediatric AIDS foundation Grant PF-77316-22 (MFS) and NIH grants RO-1 NS 26310 and RO-1 HL 61951 (KSK).

in cerebrospinal fluid and serum in human immunodeficiency virus-1 infection. J Neuroimmunol 35: 65-77.

Endres MJ, Clapham PR, Marsh M, Ahuja M, Turner JD, McKnight A, Thomas JF, Stoebenau-Haggarty B, Choe S, Vance PJ, Wells TN, Power CA, Sutterwala SS, Doms RW, Landau NR, Hoxie JA (1996). CD4-independent infection by HIV-2 is mediated by fusin/CXCR4. Cell 87: $745-756$.

Epstein LG, Sharer LR, Oleske JM, Connor EM, Goudsmit J, Bagdon L, Robert-Guroff M, Koenigsberger MR (1986). Neurologic manifestations of human immunodeficiency virus infection in children. Pediatrics 78: 678-687.

Fiala M, Looney DJ, Stins M, Way DD, Zhang L, Gan X, Chiappelli F, Schweitzer ES, Shapshak P, Weinand M, Graves MC, Witte M, Kim KS (1997). TNF-alpha opens a paracellular route for HIV-1 invasion across the bloodbrain barrier. Mol Med 3: 553-564.

Funke I, Hahn A, Rieber EP, Weiss E, Riethmuller G (1987). The cellular receptor (CD4) of the human immunodeficiency virus is expressed on neurons and glial cells in human brain. J Exp Med 165: 1230-1235.

Gelderblom HR, Hausmann EH, Ozel M, Pauli G, Koch MA (1987). Fine structure of human immunodeficiency virus (HIV) and immunolocalization of structural proteins. Virology 156: 171-176.

Grant I, Atkinson JH, Hesselink JR, Kennedy CJ, Richman DD, Spector SA, McCutchan JA (1987). Evidence for early central nervous system involvement in the acquired immunodeficiency syndrome (AIDS) and other human immunodeficiency virus (HIV) infections. Studies with neuropsychologic testing and magnetic resonance imaging [published erratum appears in Ann Intern Med 1988 Mar; 108(3):496]. Ann Intern Med 107: 828-836.

Haigwood NL, Barker CB, Higgins KW, Skiles PV, Moore GK, Mann KA, Lee DR, Eichberg JW, Steimer KS (1990). Evidence for neutralizing antibodies directed at conformational epitopes of HIV gp120. Vaccines, 90th ed. New York: Cold Spring Harbor Laboratories, pp 313320.

Healey D, Dianda L, Moore JP, McDougal JS, Moore MJ, Estess P, Buck D, Kwong PD, Beverley PC, Sattentau QJ (1990). Novel anti-CD4 monoclonal antibodies separate human immunodeficiency virus infection and fusion of CD4+ cells from virus binding. J Exp Med 172: 12331242.

Heath H, Qin S, Rao P, Wu L, LaRosa G, Kassam N, Ponath PD, Mackay CR (1997). Chemokine receptor usage by human eosinophils. The importance of CCR3 demonstrated using an antagonistic monoclonal antibody. J Clin Invest 99: 178-184.

HesselgesserJ, Taub D, Baskar P, Greenberg M, Hoxie J, Kolson DL, Horuk R (1998). Neuronal apoptosis induced by HIV-1 gp120 and the chemokine SDF-1 alpha is mediated by the chemokine receptor CXCR4. Curr Biol 8: 595-598. 
Hickstein DD, Smith A, Fisher W, Beatty PG, Schwartz BR, Harlan JM, Root RK, Locksley RM (1987). Expression of leukocyte adherence-related glycoproteins during differentiation of HL-60 promyelocytic leukemia cells. J Immunol 138: 513-519.

Hittinger G, Poggi C, Delbeke E, Profizi N, Lafeuillade A (1998). Correlation between plasma levels of cytokines and HIV-1 RNA copy number in HIV-infected patients. Infection 26: 100-103.

Huang SH (1997). Inverse PCR approach to cloning cDNA ends. Methods Mol Biol 69: 89-96.

Kalra VK, Shen Y, Sultana C, Rattan V (1996). Hypoxia induces PECAM-1 phosphorylation and transendothelial migration of monocytes. Am J Physiol 271: H2025H2034.

Kalra VK, Ying Y, Deemer K, Natarajan R, Nadler JL, Coates TD (1994). Mechanism of cigarette smoke condensate induced adhesion of human monocytes to cultured endothelial cells. J Cell Physiol 160: 154-162.

Koka P, He K, Zack JA, Kitchen S, Peacock W, Fried I, Tran T, Yashar SS, Merrill JE (1995). Human immunodeficiency virus 1 envelope proteins induce interleukin 1, tumor necrosis factor alpha, and nitric oxide in glial cultures derived from fetal, neonatal, and adult human brain. $J$ Exp Med 182: 941-951.

Lafeuillade A, Alessi MC, Poizot-Martin I, Boyer-Neumann C, Zandotti C, Quilichini R, Aubert L, Tamalet C, Juhan-Vague I, Gastaut JA (1992). Endothelial cell dysfunction in HIV infection. J Acquir Immune Defic Syndr 5: 127-131.

Lafeuillade A, Poggi C, Pellegrino P, Corti K, Profizi N, Sayada C (1996). HIV-1 replication in the plasma and cerebrospinal fluid. Infection 24: 367-371.

Lafon ME, Gendrault JL, Royer C, Jaeck D, Kirn A, Steffan AM (1993). Human endothelial cells isolated from the hepatic sinusoids and the umbilical vein display a different permissiveness for HIV1. Res Virol 144: 99104.

Lafon ME, Steffan AM, Gendrault JL, Klein-Soyer C, Gloeckler-Tondre L, Royer C, Kim A (1992). Interaction of human immunodeficiency virus with human macrovascular endothelial cells in vitro. AIDS Res Hum Retroviruses 8: 1567-1570.

Languino LR, Duperray A, Joganic KJ, Fornaro M, Thornton GB, Altieri DC (1995). Regulation of leukocyteendothelium interaction and leukocyte transendothelial migration by intercellular adhesion molecule 1fibrinogen recognition. Proc Natl Acad Sci USA 92: 1505-1509.

Lannuzel A, Barnier JV, Hery C, Huynh VT, Guibert B, Gray F, Vincent JD, Tardieu M (1997). Human immunodeficiency virus type 1 and its coat protein gp120 induce apoptosis and activate JNK and ERK mitogen-activated protein kinases in human neurons. Ann Neurol 42: 847856.

Levy JA, Hoffman AD, Kramer SM, Landis JA, Shimabukuro JM, Oshiro LS (1984). Isolation of lymphocytopathic retroviruses from San Francisco patients with AIDS. Science 225: 840-842.

Lipton SA, Yeh M, Dreyer EB (1994). Update on current models of HIV-related neuronal injury: plateletactivating factor, arachidonic acid and nitric oxide. $A d v$ Neuroimmunol 4: 181-188.

Maddon PJ, Dalgleish AG, McDougal JS, Clapham PR, Weiss RA, Axel R (1986). The T4 gene encodes the AIDS virus receptor and is expressed in the immune system and the brain. Cell 47: 333-348.

Mankowski JL, Spelman JP, Ressetar HG, Strandberg JD, Laterra J, Carter DL, Clements JE, Zink MC (1994). Neurovirulent simian immunodeficiency virus replicates productively in endothelial cells of the central nervous system in vivo and in vitro. J Virol 68: 82028208.

Matsushita S, Robert-Guroff M, Rusche J, Koito A, Hattori T, Hoshino H, Javaherian K, Takatsuki K, Putney S (1998). Characterization of a human immunodeficiency virus neutralizing monoclonal antibody and mapping of the neutralizing epitope. J Virol 62: 2107-2114.

Moses AV, Bloom FE, Pauza CD, Nelson JA (1993). Human immunodeficiency virus infection of human brain capillary endothelial cells occurs via a CD4/galactosylceramide-independent mechanism. Proc Natl Acad Sci USA 90: 10474-10478.

Nagura H, Koshikawa T, Fukuda Y, Asai J, (1986). Hepatic vascular endothelial cells heterogenously express surface antigens associated with monocytes, macrophages and T lymphocytes. Virchows Arch A Pathol Anat Histopathol 409: 407-416.

Oh SK, Cruikshank WW, Raina J, Blanchard GC, Adler WH, Walker J, Kornfeld H (1992). Identification of HIV-1 envelope glycoprotein in the serum of AIDS and ARC patients. J Acquir Immune Defic Syndr 5: 251-256.

Parnes JR (1989). Molecular biology and function of CD4 and CD8. Adv Immunol 44: 265-311.

Persidsky Y, Stins M, Way D, Witte MH, Weinand M, Kim KS, Bock P, Gendelman HE, Fiala M (1997). A model for monocyte migration through the blood-brain barrier during HIV-1 encephalitis. J Immunol 158: 3499-3510.

Poland SD, Rice GP, Dekaban GA (1995). HIV-1 infection of human brain-derived microvascular endothelial cells in vitro. J Acquir Immune Defic Syndr Hum Retrovirol 8: 437-445.

Sanchez-Pescador R, Power MD, Barr PJ, Steimer KS, Stempien MM, Brown-Shimer SL, Gee WW, Renard A, Randolph A, Levy JA (1985). Nucleotide sequence and expression of an AIDS-associated retrovirus (ARV-2). Science 227: 484-492.

Sasseville VG, Newman W, Brodie SJ, Hesterberg P, Pauley D, (1994). Monocyte adhesion to endothelium in simian immunodeficiency virus-induced AIDS encephalitis is mediated by vascular cell adhesion molecule-1/alpha 4 beta 1 integrin interactions. $A m J$ Pathol 144: 27-40.

Sasseville VG, Newman WA, Lackner AA, Smith MO, Lausen NC, Beall D, Ringler DJ (1992). Elevated vascular cell adhesion molecule-1 in AIDS encephalitis induced by simian immunodeficiency virus. Am J Pathol 141: 1021-1030.

Scandella CJ, Kilpatrick J, Lidster W, Parker C, Moore JP, Moore GK (1993). Nonaffinity purification of recombinant gp120 for use in AIDS vaccine development. AIDS Res Hum Retroviruses 9: 1233-1244.

Schneider J, Kaaden O, Copeland TD, Oroszlan S, Hunsmann G (1986). Shedding and interspecies type seroreactivity of the envelope glycopolypeptide gp120 of the human immunodeficiency virus. J Gen Virol 67 (Pt 11): 2533-2538.

Singer EJ, Syndulko K, Fahy-Chandon B, Schmid P, Conrad A, Tourtellotte WW (1994). Intrathecal IgG synthesis and albumin leakage are increased in subjects with HIV-1 
neurologic disease. J Acquir Immune Defic Syndr 7: 265271.

Stefano GB, Salzet M, Bilfinger TV (1998). Long-term exposure of human blood vessels to HIV gp120, morphine, and anandamide increases endothelial adhesion of monocytes: uncoupling of nitric oxide release. J Cardiovasc Pharmacol 31: 862-868.

Stins MF, Gilles F, Kim KS (1997). Selective expression of adhesion molecules on human brain microvascular endothelial cells. J Neuroimmunol 76: 81-90.

Strelow LI, Watry DD, Fox HS, Nelson JA (1998). Efficient infection of brain microvascular endothelial cells by an in vivo-selected neuroinvasive SIVmac variant. $J$ Neurovirol 4: 269-280.

Sultana C, Shen Y, Rattan V, Kalra VK (1996). Lipoxygenase metabolites induced expression of adhesion molecules and transendothelial migration of monocyte-like HL-60 cells is linked to protein kinase $\mathrm{C}$ activation. J Cell Physiol 167: 477-487.

Wahl LM, Corcoran ML, Pyle SW, Arthur LO, Harel-Bellan A, Farrar WL (1989). Human immunodeficiency virus glycoprotein (gp120) induction of monocyte arachidonic acid metabolites and interleukin 1. Proc Natl Acad Sci USA 86: 621-625.

Wiley CA, Schrier RD, Nelson JA, Lampert PW, Oldstone MB (1986). Cellular localization of human immunodeficiency virus infection within the brains of acquired immune deficiency syndrome patients. Proc Natl Acad Sci USA 83: 7089-7093.

Willey RL, Martin MA, Peden KW (1994). Increase in soluble CD4 binding to and CD4-induced dissociation of gp120 from virions correlates with infectivity of human immunodeficiency virus type 1. J Virol 68: 10291039.

Yeung MC, Pulliam L, Lau AS (1995). The HIV envelope protein gp120 is toxic to human brain-cell cultures through the induction of interleukin-6 and tumor necrosis factor-alpha. AIDS 9: 137-143.

Zietz C, Hotz B, Sturzl M, Rauch E, Penning R, Lohrs U (1996). Aortic endothelium in HIV-1 infection: chronic injury, activation, and increased leukocyte adherence. Am J Pathol. 149: 1887-1898. 